\title{
The Steady-State Concentration of the Species in a Reagentless Enzyme-Containing Polymer Modified Electrode Using Akbari- Ganji's method
}

\author{
S. Padma ${ }^{1}$, P. Jeyabarathi ${ }^{2}$, L. Rajendran ${ }^{1, *}$, M. E. G. Lyons ${ }^{3}$ \\ ${ }^{1}$ Department of Mathematics, AMET, Deemed to be University, Chennai, India. \\ ${ }^{2}$ Department of Mathematics, Government Arts College, Ariyalur, Affiliated to Bharathidasan \\ University,Thiruchirappalli, India \\ ${ }^{3}$ School of Chemistry and AMBER National Centre, University of Dublin, Trinity College Dublin, \\ Dublin 2, Ireland \\ *E-mail: raj_sms@ rediffmail.com
}

Received: 8 December 2021 / Accepted: 14 January 2022 / Published: 2 February 2022

\begin{abstract}
A theoretical model is presented for reagentless- conducting polymer modified electrodes. This model is based on nonlinear reaction-diffusion equation with nonlinear term related to Michaels-Menten kinetics. The theoretical representation of species concentration for steady-state conditions for all kinetic model parameters is presented in this report. Akbari-Ganji's method used is to evaluate the analytical expressions of concentration of species in the film and current. The effects of the parameter on the concentration and current are also analyzed. The limiting conditions of catalytic sites (unsaturation and site saturation) are discussed, and corresponding an analytical expression for concentrations and transient current is also derived. Our estimated analytical results are compared with the simulation results. It is observed that a good agreement has been obtained.
\end{abstract}

Keywords: Mathematical modeling; nonlinear reaction diffusion equation; enzyme, polymer modified electrode; Akbari-Ganji's method.

\section{$\underline{\text { FULL TEXT }}$}

(C) 2022 The Authors. Published by ESG (www.electrochemsci.org). This article is an open access article distributed under the terms and conditions of the Creative Commons Attribution license (http://creativecommons.org/licenses/by/4.0/). 